\title{
Impact of calcium on struvite crystal size, shape and purity
}

\author{
Kristell S. Le Corre ${ }^{1}$, Eugenia Valsami-Jones ${ }^{2}$, Phil Hobbs ${ }^{3}$, Simon A. Parsons ${ }^{1 *}$ \\ ${ }^{1}$ School of Water Sciences, Cranfield University, Cranfield MK43 OAL, UK \\ *Tel: +44 (0)1234 754841, Fax: +44 (0)1234 751671 \\ E-mail address: S.A.Parsons@Cranfield.ac.uk \\ ${ }^{2}$ Department of Mineralogy, The Natural History Museum, Cromwell Road London, SW7 5BD, \\ U.K \\ ${ }^{3}$ Institute of Grassland and Environmental Research (IGER), North Wyke, Okehampton, Devon, \\ EX20 2SB, UK
}

\begin{abstract}
Struvite precipitation occurs spontaneously in wastewater treatment plants under conditions that are influenced by many factors including concentration of $\mathrm{Mg}^{2+}, \mathrm{NH}_{4}^{+}$and $\mathrm{PO}_{4}^{3-}$ ions, $\mathrm{pH}$, temperature and mixing energy. These parameters are often difficult to control and as a result struvite generates problems of scale deposits in areas such as pipes and recirculation pumps. At the same time, struvite is considered as a potentially marketable product as an alternative fertiliser. For those two reasons, it has become important to study the principles of struvite precipitation, and to assess the parameters controlling struvite crystallisation. In the present work the influence of $\mathrm{Ca}^{2+}$ ions on the precipitation of struvite was investigated in aqueous solution containing $\mathrm{Mg}^{2+}, \mathrm{NH}_{4}^{+}$and $\mathrm{PO}_{4}^{3-}$ ions in a molar ratio 1:2:2 at room temperature and constant $\mathrm{pH}$. Different laboratory experiments have been used to assess the
\end{abstract}


effects of $\mathrm{Ca}^{2+}$ ions on size, shape, and purity of the crystals formed. Tools used include particle size analysis, X-ray diffraction (XRD) and scanning electron microscopy with energy dispersive X-ray analysis (SEM-EDS). The experimental results showed that the presence of calcium in the media can affect significantly struvite crystal growth, and the characteristics of the crystal produced.

Keywords: B1. Struvite, A1. Precipitation, A1. Crystal size and morphology, B1. Ca.

\section{Introduction}

Struvite or magnesium ammonium phosphate hexahydrate $\left(\mathrm{MgNH}_{4} \mathrm{PO}_{4} \cdot 6 \mathrm{H}_{2} \mathrm{O}\right)$ scale deposits are causing considerable concern to wastewater treatment operators $[1,2]$. The problem is not necessarily a new one as problems due to struvite spontaneous precipitation were first reported as a crust of crystalline material in 1937 in a multiple-stage sludge digestion system [3]. Often perceived as a nuisance affecting the efficiency of treatment processes and causing maintenance problems [4], the control of struvite deposition has been widely investigated, including the dilution of struvite crystals with water effluents [5]; preventive action by chemical dosing of iron salts [6] or addition of chemical inhibitors [1,7]. In the past 10 years struvite precipitation has gained interest as a route to phosphorus recovery [1]. Its composition (nitrogen $(\mathrm{N})$, phosphorus $(\mathrm{P})$ and magnesium $(\mathrm{Mg})$ ions in equal molar concentrations) makes it a potentially marketable product for the fertiliser industry, if the properties of the final product can be controlled [8]. 


\subsection{Struvite formation}

Struvite usually precipitates as stable white orthorhombic crystals in a 1:1:1 molar ratio according to equation 1 (with $\mathrm{n}=0,1$, and 2 , as a function of $\mathrm{pH}$ ) [9]:

$\mathrm{Mg}^{2+}+\mathrm{NH}_{4}^{+}+\mathrm{H}_{\mathrm{n}} \mathrm{PO}_{4}^{n-3}+6 \mathrm{H}_{2} \mathrm{O} \rightarrow \mathrm{MgNH}_{4} \mathrm{PO}_{4} \cdot 6 \mathrm{H}_{2} \mathrm{O}+\mathrm{nH}^{+}$

The occurrence and development of struvite crystals follows two chemical stages: nucleation (crystal birth) and crystal growth (enlargement of crystals until equilibrium) [10]. Predicting or controlling these stages is complex as it is controlled by a combination of factors including thermodynamic of liquid-solid equilibrium, phenomena of matter transfer between solid and liquid phases [10,11], and kinetics of reaction [12] as well as several physicochemical parameters such as: $\mathrm{pH}$ of the solution from which struvite may precipitate, supersaturation, mixing energy, temperature and presence of foreign ions.

The influence of $\mathrm{pH}$ and supersaturation on the precipitation rate and crystal characteristics of struvite has been demonstrated by a number of authors [12-16], but as yet little interest has been paid to the influence of foreign ions on struvite nucleation and crystallisation.

Theoretically speaking, impurities in solution from which a compound may precipitate can affect the growth rate of crystals due to blocking of active growth sites inhibiting the increase of crystal size, [10]. In the case of struvite crystallisation from wastewater sludge, foreign compounds are numerous (amongst them potassium, chloride, calcium, carbonates, zinc) and could perturb, be absorbed on crystal surfaces and retard struvite formation, hence phosphorus binding [17]. 
Indeed for a struvite precipitation process to be successful and economically valuable at full scale, particular attention has to be paid to the properties and quantity of the final product formed. That is to say purity and size of crystal recovered has to be controlled for a reuse as fertiliser: the strength of the granule formed has to be sufficient enough for practical reason (collection, transport and land filling) while purity is essential for environmental reasons.

\subsection{Influence of calcium and carbonate ions}

The way calcium and carbonate ions could affect struvite nucleation and growth is particularly of interest as their levels in wastewater effluent are relatively high. The study published by Parsons et al., 2001 mentioned magnesium to calcium ratio $(\mathrm{Mg}: \mathrm{Ca})$ ranging from 1:1.4 to 1:3.7 in settled sludge liquors from various wastewater treatment plant in the UK [18]. While it is also not unusual to find carbonates $\left(\mathrm{CO}_{3}^{2-}\right)$ concentrations, (measured in terms of alkalinity, i.e. $\mathrm{mg} / \mathrm{L}$ as $\mathrm{CaCO}_{3}$ ) above $200 \mathrm{mg} / \mathrm{L}$ in various streams of sewage treatment works [19].

Although few authors have studied the influence of calcium and carbonates on struvite crystallisation, it has been showed previously that the presence of calcium $\left(\mathrm{Ca}^{2+}\right)$ or carbonates ions $\left(\mathrm{CO}_{3}^{2-}\right)$ in the media where struvite precipitates can lengthen the induction time preceding

the first occurrence of crystals and affect negatively the growth rate $[16,17,20] . \mathrm{Ca}^{2+}$ ions interact effectively with phosphate or carbonate ions to form calcium phosphates (in wastewater systems commonly a poorly crystallised hydroxylapatite) or calcium carbonate according to the following equations:

$$
\begin{aligned}
& 5 \mathrm{Ca}^{2+}+3 \mathrm{PO}_{4}^{3-}+\mathrm{H}_{2} \mathrm{O} \rightarrow \mathrm{Ca}_{5}\left(\mathrm{PO}_{4}\right)_{3} \mathrm{OH}+\mathrm{H}^{+} \\
& \mathrm{Ca}^{2+}+\mathrm{CO}_{3}^{2-} \rightarrow \mathrm{CaCO}_{3}
\end{aligned}
$$


The presence of $\mathrm{Ca}$ ions can influence struvite formation, either by competing for phosphate ions or by interfering with the crystallisation of struvite. In the latter case, the characteristics of struvite crystals formed are likely to be affected; but this has never been assessed. The main objective of this paper is thus to explore how $\mathrm{Ca}$ ions can affect struvite crystals nucleation and growth, and discuss the impact this has on the quality of the recovered product.

\section{Materials and methods}

A series of experiments have been undertaken to assess the impact of $\mathrm{Ca}$ ions on struvite crystallisation using absorbance measurements, particle size analysis and the characterisation of struvite crystals formed through X-ray diffraction (XRD) and scanning electron microscopy coupled with energy dispersive X-ray analysis (SEM-EDS).

For all the experiments reported here struvite was precipitated from mixed solutions of magnesium chloride hexahydrate $\left(\mathrm{MgCl}_{2} \cdot 6 \mathrm{H}_{2} \mathrm{O}\right)$ and ammonium phosphate $\left(\mathrm{NH}_{4} \mathrm{H}_{2} \mathrm{PO}_{4}\right)$. Stock solutions of magnesium chloride hexahydrate $\left(\mathrm{MgCl}_{2} \cdot 6 \mathrm{H}_{2} \mathrm{O} / \mathrm{BDH}\right.$ AnalaR) $0.05 \mathrm{M}$ and ammonium phosphate $\left(\mathrm{NH}_{4} \mathrm{H}_{2} \mathrm{PO}_{4}\right.$ / Sigma ACS Reagent) $0.2 \mathrm{M}$ were prepared by dissolving the corresponding crystalline compounds in ultra-pure water (Purelab Ultra, Elga). Each stock solution was then filtered through a $0.22 \mu \mathrm{m}$ paper filter to eliminate the presence of impurities, and stored at room temperature. All the experiments mentioned in the present paper have been undertaken at room temperature. 


\section{1. $p H$ and absorbance experiments}

Initial experiments used changes in solution $\mathrm{pH}$ to indicate the start and rate of nucleation. Experiments at various initial $\mathrm{Mg}$ concentrations were carried out to determine an initial $\mathrm{Mg}$ concentration for which the induction period is reasonable and the nature of the crystal formed acceptable.

Struvite was precipitated from volumes of stock solutions $\mathrm{MgCl}_{2} \cdot 6 \mathrm{H}_{2} \mathrm{O}$ and $\mathrm{NH}_{4} \mathrm{H}_{2} \mathrm{PO}_{4}$ diluted in $250 \mathrm{~mL}$ flasks so that the final concentration of $\mathrm{Mg}$ after mixing ranged from $1.2 \mathrm{mM}$ to $3.5 \mathrm{mM}$ and the molar ratio of magnesium, nitrogen and phosphorus (Mg: $\mathrm{N}: \mathrm{P})$ always equal 1:2:2. Prior to mixing, the diluted solutions were adjusted to $\mathrm{pH} 9$, by addition of sodium hydroxide (analytical reagent grade) $0.01 \mathrm{~N}$ and $2 \mathrm{~N}$ and then the two solutions were simultaneously mixed together in a $600 \mathrm{~mL}$ beaker, and the $\mathrm{pH}$ was measured periodically over 25 minutes. At the end of each test, the precipitate was filtered through a $0.22 \mu \mathrm{m}$, dried at room temperature and then characterised via XRD (Powder X-Ray Diffractometer D5005 Siemens) and SEM-EDS (Philips XL 30 SFEG).

The influence of $\mathrm{Ca}$ ions on absorbance during struvite crystallisation was investigated at constant initial $\mathrm{Mg}$ concentration $\left(\left[\mathrm{Mg}^{2+}\right]=1.64 \mathrm{mM}\right)$ and at a wavelength of $385 \mathrm{~nm}$.

$\mathrm{Ca}$ ions were added in the $\mathrm{Mg}$ chloride solution as $\mathrm{Ca}$ chloride dihydrate $0.4 \mathrm{M}\left(\mathrm{CaCl}_{2} \cdot 2 \mathrm{H}_{2} \mathrm{O} /\right.$ Fisher Chemicals) and carbonates ions were added in the ammonium phosphate solution as sodium hydrogen carbonate $0.4 \mathrm{M}\left(\mathrm{NaHCO}_{3} /\right.$ AnalaR Fisher Chemicals) to provide alkalinity so that the solutions were better analogues to real media (i.e.: wastewater effluents/sludge liquors). The molar ratios $\mathrm{Mg}: \mathrm{Ca}: \mathrm{CO}_{3}$ investigated were $2: 1: 1,1: 1: 1$ and 1:2:2. 


\subsection{Particle sizing experiments and crystal characterisation}

The effects of $\mathrm{Ca}$ ions on struvite crystal size, shape and purity were then investigated using particle size analysis, SEM, and XRD. Here a Mastersizer 2000 combined with a Hydro 2000MU (Malvern instruments) was used to follow changes in particle size distribution during struvite crystallisation in presence of $\mathrm{Ca}$ ions. Struvite was precipitated in a $1 \mathrm{~L}$ beaker from equal volumes (400 mL) of $\mathrm{MgCl}_{2} \cdot 6 \mathrm{H}_{2} \mathrm{O}$ and $\mathrm{NH}_{4} \mathrm{H}_{2} \mathrm{PO}_{4}$ so that the $\mathrm{Mg}$ concentration in the final solution was $1.64 \mathrm{mM}$ and the ratio of $\mathrm{Mg}: \mathrm{N}: \mathrm{P}$ was $1: 2: 2$. Prior to mixing, various volumes of $\mathrm{CaCl}_{2} \cdot 2 \mathrm{H}_{2} \mathrm{O} 0.4 \mathrm{M}$ were added to the $\mathrm{Mg}$ chloride solution, and equal volumes of $\mathrm{NaHCO}_{3} 0.4 \mathrm{M}$ were added in the ammonium phosphate solution. Then each solution was $\mathrm{pH}$ adjusted to 9 by addition of $\mathrm{NaOH}$. Ratios $\mathrm{Mg}: \mathrm{Ca}: \mathrm{CO}_{3}$ experimented were 2:1:1, 1:1:1 and 1:2:2. The particle size distribution was automatically recorded as the experiment progressed. At the end of each experiment, the samples were filtered through $0.22 \mu \mathrm{m}$ filter, dried at room temperature and analysed with XRD and SEM-EDS.

\section{Results and discussion}

\section{$3.1 \mathrm{pH}$}

Struvite crystallisation is governed by the combination of key parameters amongst which are the $\mathrm{pH}$, the initial concentration of the ionic species in solution, the mixing speed and the presence of foreign ions. In order to assess the impact of $\mathrm{Ca}$ ions on the quality, that is to say here size, morphology and purity, of struvite crystals, it was necessary to limit the impact of the other parameters on crystal formation. Experiments were undertaken at room temperature and 
at a constant mixing speed. Solutions were made to a standard recipe with the molar ratio $\mathrm{Mg}: \mathrm{N}: \mathrm{P}(1: 2: 2)$ leaving the concentration of $\mathrm{Mg}$ as the limiting parameter.

The initial experiments undertaken used $\mathrm{pH}$ as an indicator of struvite nucleation. As struvite precipitates, it triggers a release of protons ions in solution and hence a change in $\mathrm{pH}$ occurs during the nucleation process. The drop in $\mathrm{pH}$ is characteristic of the speed at which the first crystals of struvite occurs, and is linked to the rate of struvite formation which can influence the quality of the crystals formed.

The first series of tests measured changes of $\mathrm{pH}$ with time for a range of $\mathrm{Mg}$ concentrations. It was seen that as expected increasing the concentration of the limiting $\mathrm{Mg}$ ions lead to an increase in the change in $\mathrm{pH}$ and a reduction in induction time (Figure 1). XRD and SEM were used to characterise the purity and morphology of the produced crystals. Little difference in purity was observed but the morphology of the crystals was influenced by the initial concentration of $\mathrm{Mg}$ in solution. When the $\mathrm{Mg}$ concentration increases, the characteristics of struvite crystals is better, that is to say that the typical orthorhombic shape of struvite is more frequent and their size is bigger. From these experiments the Mg concentration of $1.64 \mathrm{mM}$ was chosen as a good compromise between induction period and quality of the resulting product.

\subsection{Effects of Ca ions on absorbance during struvite crystallisation}

In addition to $\mathrm{pH}$, absorbance measurements have often been used to follow nucleation and growth [21]. The absorbance measurement corresponds to the quantity of energy absorbed (or transmitted) by the matter, and hence following the evolution of the absorbance of a 
solution at a specific wavelength, we can see the advancement of the crystallisation process and hence the evolution of the particle growth.

Here we have investigated the effect that $\mathrm{Mg}: \mathrm{Ca}$ ratio has on struvite nucleation and growth. Without any $\mathrm{Ca}$ the absorbance increases quickly (less than 2 minutes) due to the nucleation of struvite particles, before reaching a maximum stable value (around 0.170) corresponding to crystal growth and sedimentation stages (Figure 2). By adding $\mathrm{Ca}$ at a molar ratio of $\mathrm{Mg}: \mathrm{Ca} 2: 1$, we observe an increase in absorbance values, probably due to the formation of $\mathrm{Ca}$ carbonate or phosphate but we also notice an increase in the induction time from 2 minutes to more than 3 minutes. At the higher molar ratios $\mathrm{Mg}: \mathrm{Ca} 1: 1$, and 1:2, the turbidity of the solution just after mixing is high due to the preferential reaction of $\mathrm{Ca}$ ions with carbonate or phosphate ions making it difficult to extract data on the formation of struvite crystals.

At a molar ratio $\mathrm{Mg}: \mathrm{Ca} 2: 1$, it appears that an instantaneous precipitation occurs in the early stage of the reaction causing the initial turbidity of the solution, but the time taken to reach constant absorbance values is not as quick as it was during the first experiment without Ca. Despite this first reaction, some particles continue thus to nucleate. As phosphate ions are present in this case in large excess comparing to calcium, even if the totality of $\mathrm{Ca}$ ions react preferentially with phosphates to form calcium phosphate, the minimum 1:1:1 Mg:N:P ratio necessary for struvite to occur is still available, this would explain that struvite nucleation is possible. At this level, calcium ions could thus affect the rate of growth and the induction time as Koutsoukos et al., 2003 mentioned it in their work [17]. At higher molar ratios $\mathrm{Mg}: \mathrm{Ca}$ 1:1, and $1: 2$, the results are more difficult to interpret as although the turbidity of the solution just after mixing is high due to the preferential reaction of $\mathrm{Ca}$ ions with carbonate or phosphate ions, making it difficult to extract data from absorbance measure on the formation of struvite crystals. To understand what happens in those cases in terms of crystal formation and/or 
characteristics of the compound generated, analysis of the recovered product was necessary. To clarify these first statements the following experiments concerning particle sizing and crystal characterisation were carried out.

\subsection{Particle sizing experiments and crystals characterisation}

To determine the influence of $\mathrm{Ca}$ ions at higher concentrations, and to investigate their effect on the struvite crystal properties, it was decided to undertake a series of experiments using particle sizing, XRD and SEM-EDS. Particle size measurements were performed continuously at constant speed $(\mathrm{Vr}=2500 \mathrm{rpm})$ during the precipitation process and the particle size was recorded over periodic intervals. Again changes in particle size were followed for a range of $\mathrm{Mg}: \mathrm{Ca}$ ratios. As a reference the change in particle size in a solution without added $\mathrm{Ca}$ was measured and the data obtained showed a monomodal particle size distribution for all the distributions, with a mean size rising to constant values comprised between 13.416 and 15.157 $\mu \mathrm{m}$ after 5 minutes of experiment (Figure 3, Figure 4).

The effects of $\mathrm{Ca}$ concentration on the evolution of struvite particle size are showed here by plotting the particle size distribution at the beginning ( $\mathrm{T}=5 \mathrm{~min}$ ) and the end ( $\mathrm{T}=20 \mathrm{~min}$ ) of the experiment. An increase of the Ca concentration in relation to the $\mathrm{Mg}$ concentration results in a decrease of the mean size measured after 5 minutes run: maximum peaks are recorded between $2.15 \mu \mathrm{m}$ to $2.429 \mu \mathrm{m}$ for the ratio $2: 1,2.745 \mu \mathrm{m}$ to $3.101 \mu \mathrm{m}$ for the ratio $1: 1$ and $3.958 \mu \mathrm{m}$ to $4.472 \mu \mathrm{m}$ for the ratio $1: 2$. After 20 minutes run, the results are different. The distribution in presence of $\mathrm{Ca}$ ions at low concentration (ratio $\mathrm{Mg}: \mathrm{Ca} 2: 1$ ) appears with a maximum peak corresponding to a mean size of particle lower than for the run without $\mathrm{Ca}$. At higher Ca concentrations (ratios 1:1, and 1:2), the data showed a rise in the population of 
particles with higher mean size (Figure 4) than for the results without $\mathrm{Ca}$ addition. This may indicate an agglomeration of the particles so that the percentage of individual particles decreases compared to the agglomerates. SEM pictures taken of dried samples recovered at the end of each trial helped to explain this supposition.

Firstly, the XRD pattern generated from the sample without Ca matched with the database model for struvite (i.e. position and intensity of the peaks, figure 5, sample 1), identifying the precipitate to be struvite [19]. But as Ca concentration increases (Mg:Ca 2:1, figure 5, sample 2), XRD results showed a more noisy pattern with reduction in peak size and definition. At higher $\mathrm{Ca}$ concentrations the analysis revealed only background noise, indicating that there was no macro crystalline compound present in the samples (Figure 5, XRDs of samples 3 and 4). SEM confirmed the results of the particle size experiments and XRD analysis in that the formation of struvite crystals (Figure 5, picture sample 1) is affected by the presence of Ca ions. At a low calcium concentration in solution, we can still distinguish the shape of struvite particle but covered by a precipitate (Figure 5, picture sample 2) whilst a rise to higher $\mathrm{Ca}$ concentration inhibits the occurrence of struvite crystals and leads to the formation an amorphous matter (Figure 5, pictures sample 3 and 4), probably a calcium phosphate compound. To identify the elemental composition of this amorphous matter, energy dispersive spectrometry has been used on specific area localised on the SEM pictures.

As expected for samples without Ca, EDS spectrum (Figure 6, Sample1) showed highest peaks were obtained for $\mathrm{Mg}, \mathrm{P}$ and $\mathrm{O}$ (i.e.: major elements composing struvite in mass percentage), confirming the purity of the crystal formed as no traces of other compounds have been found. At a $\mathrm{Mg}$ :Ca ratio of 2:1, EDS performed on struvite like crystals covered with an amorphous substance, showed the presence of a distinctive peak for $\mathrm{Ca}$ while peaks for $\mathrm{Mg}$ and $\mathrm{P}$ were quasi unchanged (Figure 6, Sample2 A). We can say that at this level another phase precipitates 
on struvite crystal surfaces and around, hence starting to interact with its formation. It is more than just calcium which is absorbed on the surface of struvite crystals. An EDS analysis performed on an amorphous part next to the crystal like shape in the same sample (Figure 6, Sample2 B) revealed a higher peak for $\mathrm{Ca}$ and an important peak for phosphorus when compared to the magnesium. The formation of this precipitate at the surface of crystals would thus explain the multitude of background noises observed previously on the XRD patterns (Figure 5, sample2) while struvite peaks are still identifiable.

At $\mathrm{Mg}: \mathrm{Ca}$ 1:1 and above (Figure 6, samples 3 and 4), the EDS spectrum of this amorphous matter reinforce the first hypothesis that the precipitate formed at this stage is due to the formation of an amorphous calcium phosphate. Indeed both spectra show prominent peaks for phosphorus and calcium when compared to magnesium. From a first point of view, we could have identified it as either an amorphous calcium phosphate or another calcium phase (i.e. calcium carbonate or calcium hydroxide), but in the latter case XRD pattern for samples 2 to 4 would have showed them on Figure 5, as they are crystalline substances. This confirms thus that the chemical nature of this matter is easily assimilated as an amorphous calcium phosphate.

\section{Conclusion}

The impact of $\mathrm{Mg}$ and $\mathrm{Ca}$ solution concentrations on struvite crystallisation has been investigated using a range of analytical tools including $\mathrm{pH}$, absorbance, particle size, XRD and SEM-EDS.

It has been shown that the presence of $\mathrm{Ca}$ ions in solution has a significant impact on struvite crystallisation in terms of size shape and purity of the product recovered. In the present study, it has been found that increasing the calcium concentration reduces the crystal size and inhibits 
the struvite growth, or affects struvite crystallisation and leads to the formation of an amorphous substance rather than crystalline struvite.

At molar ratios $\mathrm{Mg}: \mathrm{Ca} \sim 1: 1$ and above, no more crystalline compound is formed but a substance identified as an amorphous calcium phosphate.

As $\mathrm{Ca}$ ions levels in sludge liquors are high in relation with $\mathrm{Mg}$ levels, Ca impact on struvite crystal morphology will have to be considered in the future in order to improve the recovery and reuse as a fertiliser.

Further works will thus focus on the extrapolation of these laboratory results using a reactor which has been designed and is currently being used to study struvite nucleation and growth at larger scale.

\section{References}

[1] Doyle J.D.,Oldring K., Churchley J., Price C., Parsons S.A., Chemical control of struvite precipitation. Journal of Environmental Engineering-ASCE, 129 (5), 419-426 (2003).

[2] Doyle J.D., Parsons S.A., Struvite formation, control and recovery. Water Res., 36, 39253940 (2002).

[3] Rawn A.M., Perry Banta A. and Pomeroy R., Multiple-stage sewage sludge digestion. American Society of Civil Engineers, 93-132 (1937).

[4] Mohajit X., Bhattarai K.K., Taiganides E.P. and Yap B.C., Struvite deposits in pipes and aerators. Biological Wastes, 30, 133-147 (1989).

[5] Borgerding J., Phosphate deposits in digestion systems. Journal WPCF, 44, 813-819 
(1972).

[6] Mamais D., Pitt P.A., Cheng Y.W., Loiacono J. and Jenkins D., Determination of ferricchloride dose to control struvite precipitation in anaerobic sludge digesters. Water Environment Research, 66 (7), 912-918 (1994).

[7] Snoeyink V.L and Jenkins D., Water Chemistry . John Wiley and sons, New York, (1980).

[8] Booker N.A., Priestley A.J. and Fraser I.H., Struvite formation in wastewater treatment plants: opportunities for nutrient recovery. Environmental Technology, 20, 777-782 (1999).

[9] Abbona F. and Boistelle R., Growth morphology and crystal habit of struvite crystals $\left(\mathrm{MgNH}_{4} \mathrm{PO}_{4} .6 \mathrm{H}_{2} \mathrm{O}\right)$. Journal of Crystal Growth, 46, 339-354 (1979).

[10] Jones A.G., Crystallization process system. Butterworth, Heinemann, Great Britain, (2002).

[11] Mullin J.W., Crystallization. Butterworth, Heinemann, Great Britain, (1992).

[12] Ohlinger K.N., Young T.M. and Schroeder E.D., Kinetics effects on preferential struvite accumulation in wastewater. Journal of Environmental Engineering, 125, 730-737 (1999).

[13] Stratful I., Scrimshaw M.D. and Lester J.N., Conditions influencing the precipitation of magnesium ammmonium phosphate. Water Res., 35, 4191-4199 (2001).

[14] Kofina A.N. and Koutsoukos P.G., Nucleation and crystal growth of struvite in aqueous media. New prospectives in phosphorus recovery. Wasic Workshop, Istanbul (Turkey), (2003).

[15] Abbona F. and Boistelle R., Nucleation of struvite $\mathrm{MgNH}_{4} \mathrm{PO}_{4} \cdot 6 \mathrm{H}_{2} \mathrm{O}$. Single crystals and 
aggregates. Crystal Res. and Technol., 20, 133-140 (1985).

[16] Bouropoulos N.Ch. and Koutsoukos P.G., Spontaneous precipitation of struvite from aqueous solutions. Journal of Crystal Growth, 213, 381-388 (2000).

[17] Koutsoukos P.G., Kofina A.N., Klepetsanis, P.G, Exploration of alternatives for phosphorus recovery from wastewater by crystallisation. WASIC workshop, Istanbul (Turkey), (2003).

[18] Parsons S.A., Wall F., Doyle J., Oldring K., Churchley J., Assessing the potential for struvite recovery at sewage treatment works. Environmental Technology, 22 (11), 1279-1286 (2001).

[19] Jaffer Y., Clark T.A., Pearce P. and Parsons S.A., Potential phosphorus recovery by struvite formation. Water Res., 36, (7), 1834-1842 (2002)

[20] Kofina A.N. and Koutsoukos P.G, Nucleation and growth of struvite from synthetic wastewater. International Conference on struvite: its role in phosphorus recovery and reuse, Cranfield (UK), (2004).

[21] Barett R.A. and Parsons S.A., The influence of magnetic fields on calcium carbonate precipitation. Water Res., 32, 609-612 (1998).

[22] Mineral data base PCPDFWIN version 1.3. 


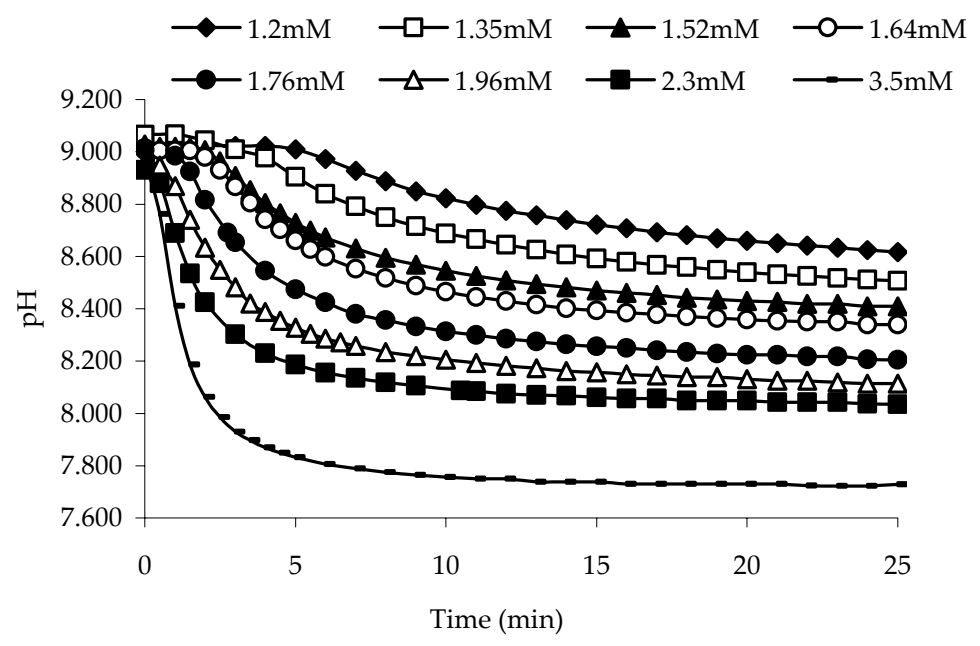

Fig. 1. Evolution of $\mathrm{pH}$ during struvite crystallisation for different initial $\mathrm{Mg}$ concentration

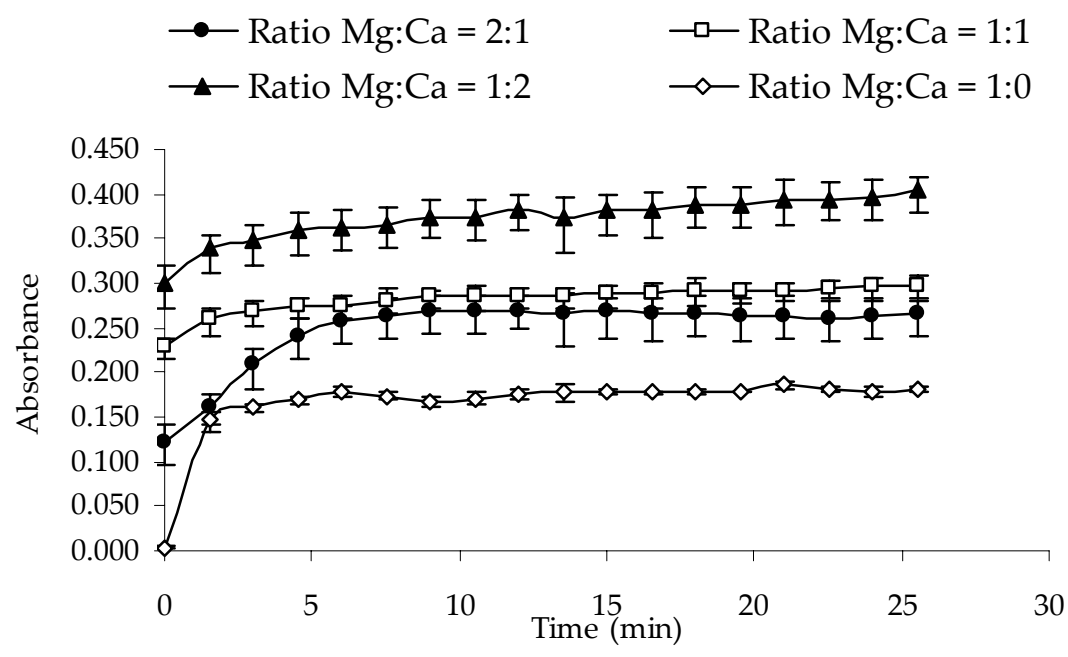

Fig. 2. Influence of increasing addition of $\mathrm{Ca}$ on absorbance measurements during struvite crystallisation 


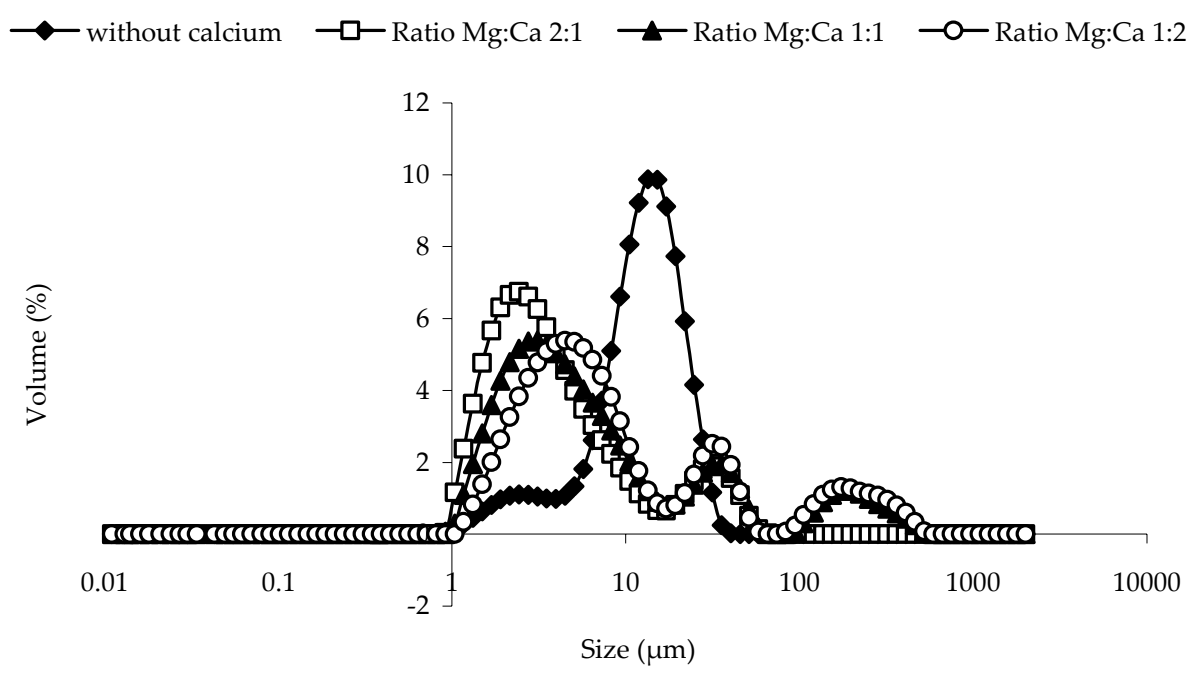

Fig. 3. Particle size distribution five minutes after the mix of the solutions for different molar ratio $\mathrm{Mg}: \mathrm{Ca} .\left(\mathrm{V}_{\text {mixing }}=2500 \mathrm{rpm}\right)$

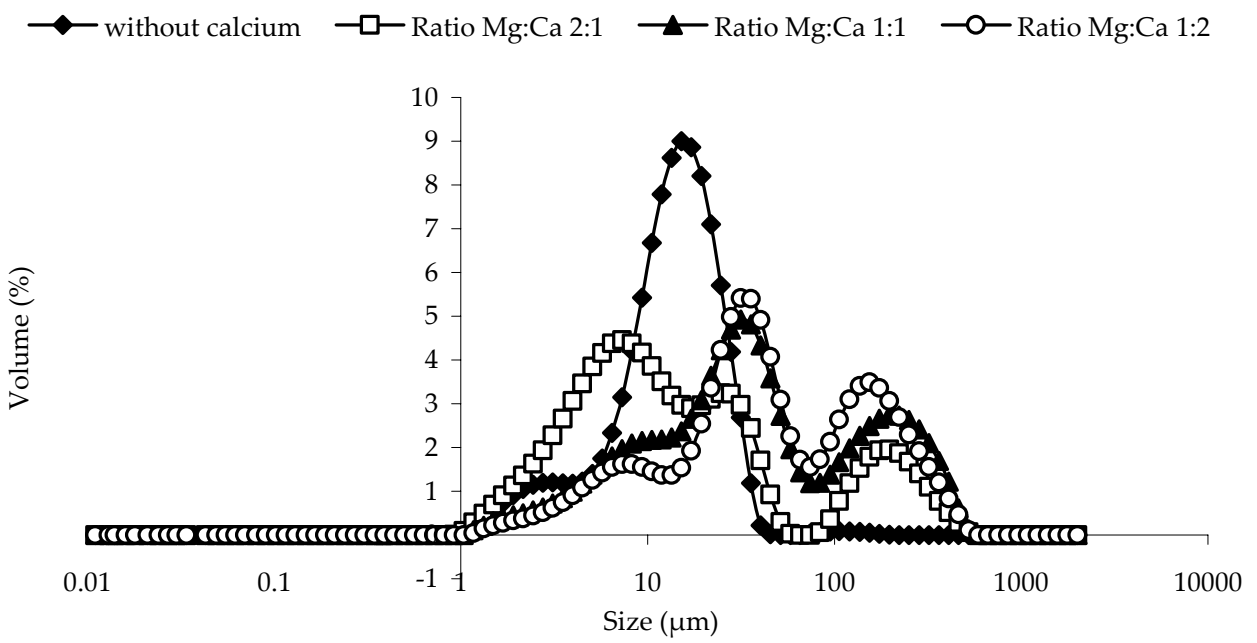

Fig. 4. Particle size distribution 20 minutes after the mix of the solutions for different molar ratio $\mathrm{Mg}: \mathrm{Ca} .\left(\mathrm{V}_{\text {mixing }}=2500 \mathrm{rpm}\right)$ 



\section{Sample 4: \\ $[\mathrm{Mg}]=1.64 \mathrm{mM}$}

Ratio $\mathrm{Mg}: \mathrm{Ca}=1: 2$

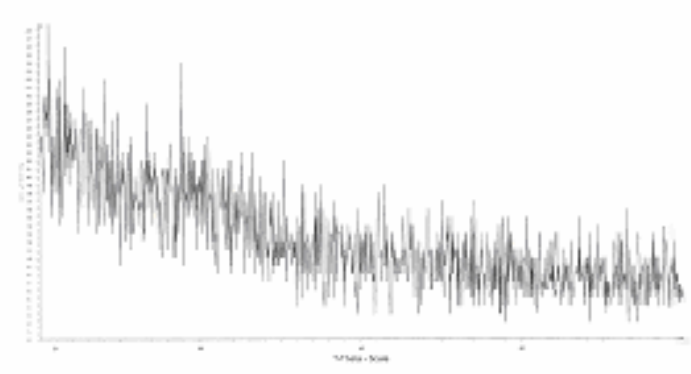

Fig. 5. Impact of growing amounts of Ca ions on struvite crystal morphology and purity. SEM pictures and their respective X-ray diffractograms 

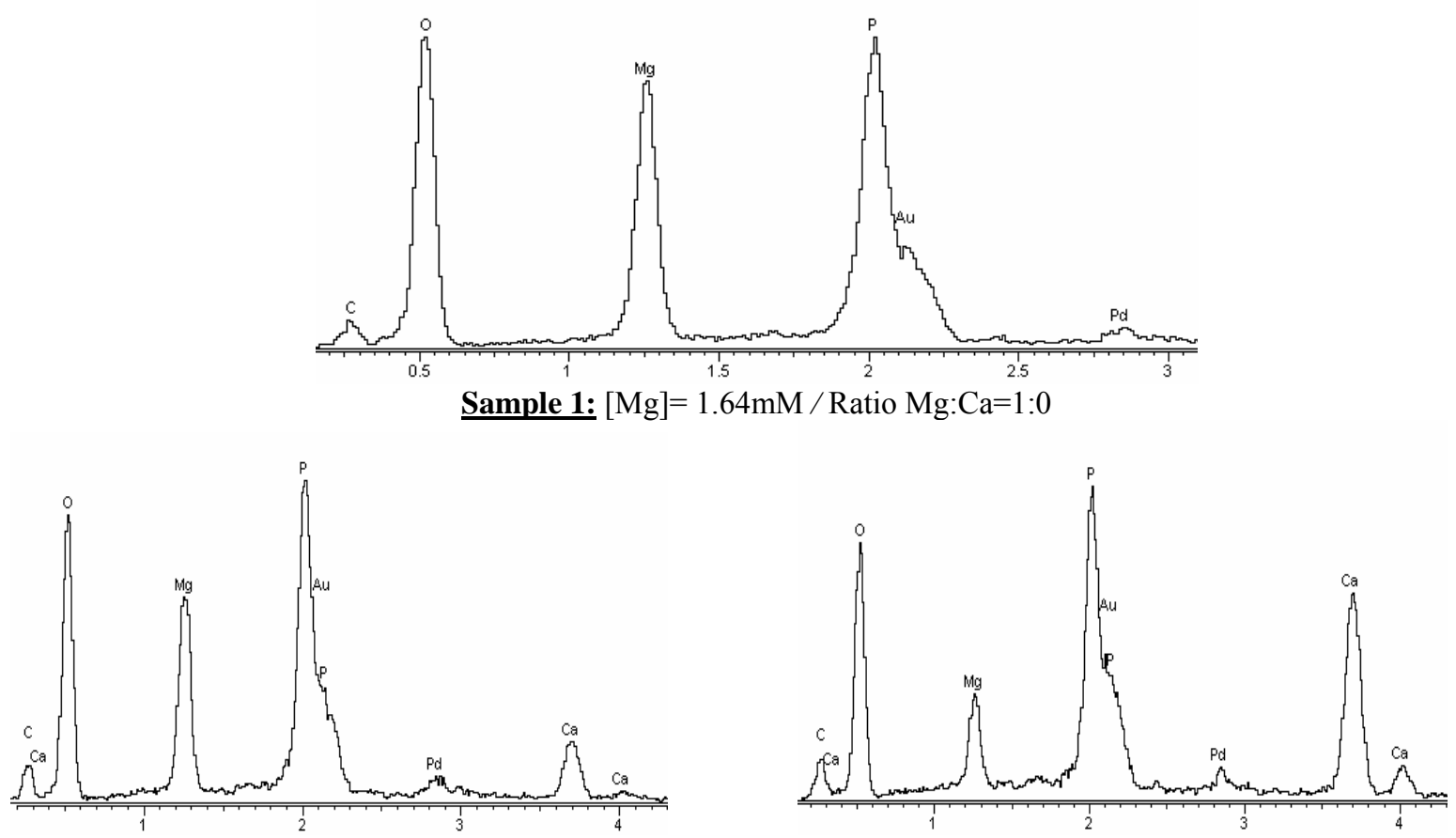

A

Sample 2: $[\mathrm{Mg}]=1.64 \mathrm{mM} /$ Ratio $\mathrm{Mg}: \mathrm{Ca}=2: 1$

B



Sample 3: $[\mathrm{Mg}]=1.64 \mathrm{mM} /$ Ratio $\mathrm{Mg}: \mathrm{Ca}=1: 1$

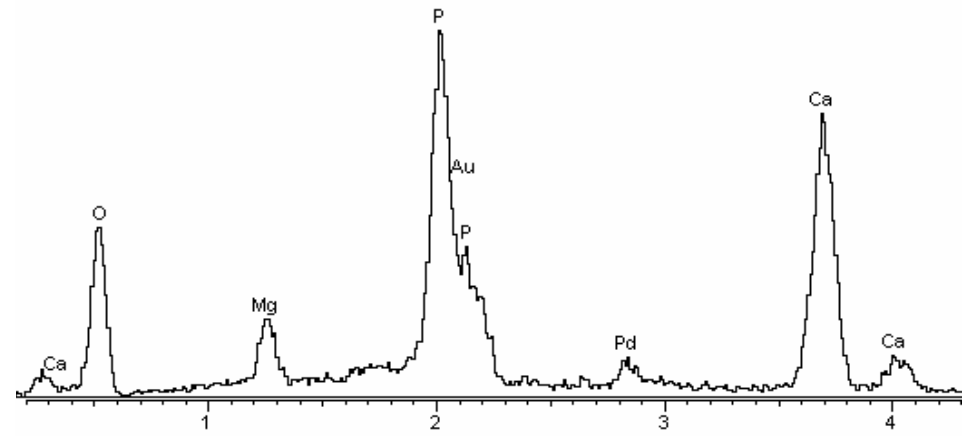

Sample 4: $[\mathrm{Mg}]=1.64 \mathrm{mM} /$ Ratio $\mathrm{Mg}: \mathrm{Ca}=1: 2$

Fig. 6. Impact of growing amounts of $\mathrm{Ca}$ ions on struvite crystallisation. Elemental surface analysis by EDS. 